\title{
Inhibition of dengue virus replication by diisopropyl chrysin-7-yl phosphate
}

\author{
Jiang Du, Zhe Chen, Ting Zhang, Jianmin Wang ${ }^{*} \&$ Qi Jin ${ }^{* *}$ \\ MOH Key Laboratory of Systems Biology of Pathogens, Institute of Pathogen Biology, Chinese Academy of Medical Sciences \& Peking Union \\ Medical College, Beijing 100176, China
}

Received December 12, 2015; accepted February 6, 2016; published online April 21, 2016

\begin{abstract}
Dengue fever is a tropical disease and caused by dengue virus (DENV), which is transmitted by mosquitoes and infects about 400 million people annually. With the development of international trade and travel, China is facing a growing threat. Over 40 thousands of people were infected during the 2014 DENV outbreak in Guangdong. Neither licensed vaccine nor therapeutic drug has been available. In this report, we isolated two clinical DENV strains. The full-length genome was sequenced and characterized. We also applied a flavonoid, CPI, into an anti-DENV assay. Replication of viral RNA and expression of viral protein was all strongly inhibited. These results indicated that CPI may serve as potential protective agents in the treatment of patients with chronic DENV infection.
\end{abstract}

dengue virus, virus isolation, phylogenetic analysis, antiviral activity, flavonoid

Citation: $\quad$ Du, J., Chen, Z., Zhang, T., Wang, J., and Jin, Q. (2016). Inhibition of dengue virus replication by diisopropyl chrysin-7-yl phosphate. Sci China Life Sci 59, 832-838. doi: 10.1007/s11427-016-5050-5

\section{INTRODUCTION}

Dengue fever is a mosquito-borne tropical disease caused by the dengue virus (DENV). DENV belongs to the Flaviviridae family. Usually, the virus is transmitted to humans by the bite of infected Aedes aegypti or Aedes albopictus mosquitoes (Higa, 2011). There are four DENV serotypes (DENV1-4) (Holmes and Twiddy, 2003; Vasilakis and Weaver, 2008). Infection with any one of the four serotypes can lead to dengue fever. Clinically, fever, rash, lethargy and joint pain are the most common presentations. A small proportion of severe cases could develop into dengue haemorrhagic fever or dengue shock syndrome, or even result in death. A fifth DENV serotype was detected in 2013 (Normile, 2013). The DENV genome contains about 11,000 nucleotide bases, which code for the three structural proteins $(\mathrm{C}, \mathrm{prM}$ and $\mathrm{E})$ that form the viral particles and seven

*Corresponding author (email: jianminwang@ipbcams.ac.cn) **Corresponding author (email: zdsys@ vip.sina.com) other non-structural proteins (NS1, NS2a, NS2b, NS3, NS4a, NS4b, NS5) that are only found in infected host cells and are involved in viral replication.

About 400 million people worldwide are infected with DENV annually (Bhatt et al., 2013; Thomas and Endy, 2011). In mainland China, from 1978 to 2008, a total of 655,324 cases of dengue fever, including 610 deaths, were reported (Wu et al., 2010). From 2009 to 2014, 52,749 cases and six deaths were notified (Chen and Liu, 2015). Unfortunately, neither commercially vaccine nor antiviral treatment for DENV is available. Clinical infections are usually treated with supportive treatment, by using either oral or intravenous rehydration. An effective antiviral therapy against DENV infection is urgently needed.

Flavonoids are a large group of naturally occurring phenylchromones and are present in all vascular plants. Antiviral activities of numerous flavonoids have been reported. Replication of a number of viruses can be inhibited by baicalein, a member of the flavone subgroup of flavonoids, 
including herpes simplex viruses 1 and 2 (HSV-1 and HSV-2) and Japanese encephalitis virus (JEV) (Johari et al., 2012; Lyu et al., 2005). In our previous study, we showed that 7-hydroxyflavone and 5,7-dihydroxyflavone substantially inhibited replication of enterovirus 71 in infected cells (Wang et al., 2014a, 2014b). It has been reported that extract of scutellaria baicalensis, which is rich in baicalein, reduced all four types of DENV infectivity and replication in cells (Zandi et al., 2013). Quercetin also demonstrated anti-DENV2 inhibitory activities in vitro (Zandi et al., 2011).

In this study, we isolated a clinical DENV1 strain and a DENV2 strain from patients with dengue infection. The genome was sequenced and characterized, which provided useful information to understand the DENV epidemic in China. We also tested the antiviral activity of diisopropyl chrysin-7-yl phosphate (CPI). CPI exhibited potent antiviral activity against both DENV1 and DENV2.

\section{RESULTS}

Acute phase serum from the patients who were clinically diagnosed as severe dengue fever was detected with DENV primers. PCR positive samples were inoculated in VERO cells. Cells were propagated for several passages until clear cytopathic effect (CPE) was observed. Viral RNA was extracted from cell culture supernatant and checked with DENV type specific primers. A DENV1 isolate and a DENV2 isolate was determined and the full-length genome was sequenced.

The newly isolated DENV1 was named as SZ/2015. The complete genome sequences were submitted to GenBank under the accession number KU094071. The entire genome is 10,736 nt in length. Phylogenetic analysis of DENV1 based on $\mathrm{E}$ gene is shown in Figure 1. The newly isolated DENV1/SZ/2015 belonged to the genotype American/Asian, clustering closely with the Indonesia/2015 isolate and two Pakistan/2014 isolates. At meanwhile, other DENV1 strains isolated in the first ten years of this century from China and other Southeast Asian countries mainly located in the Asian genotype. The newly isolated DENV2/ SZ/2015 was also sequenced and the complete genome sequences were submitted to GenBank under the accession number KU094070. The entire genome is $10,723 \mathrm{nt}$ in length. Phylogenetic analysis

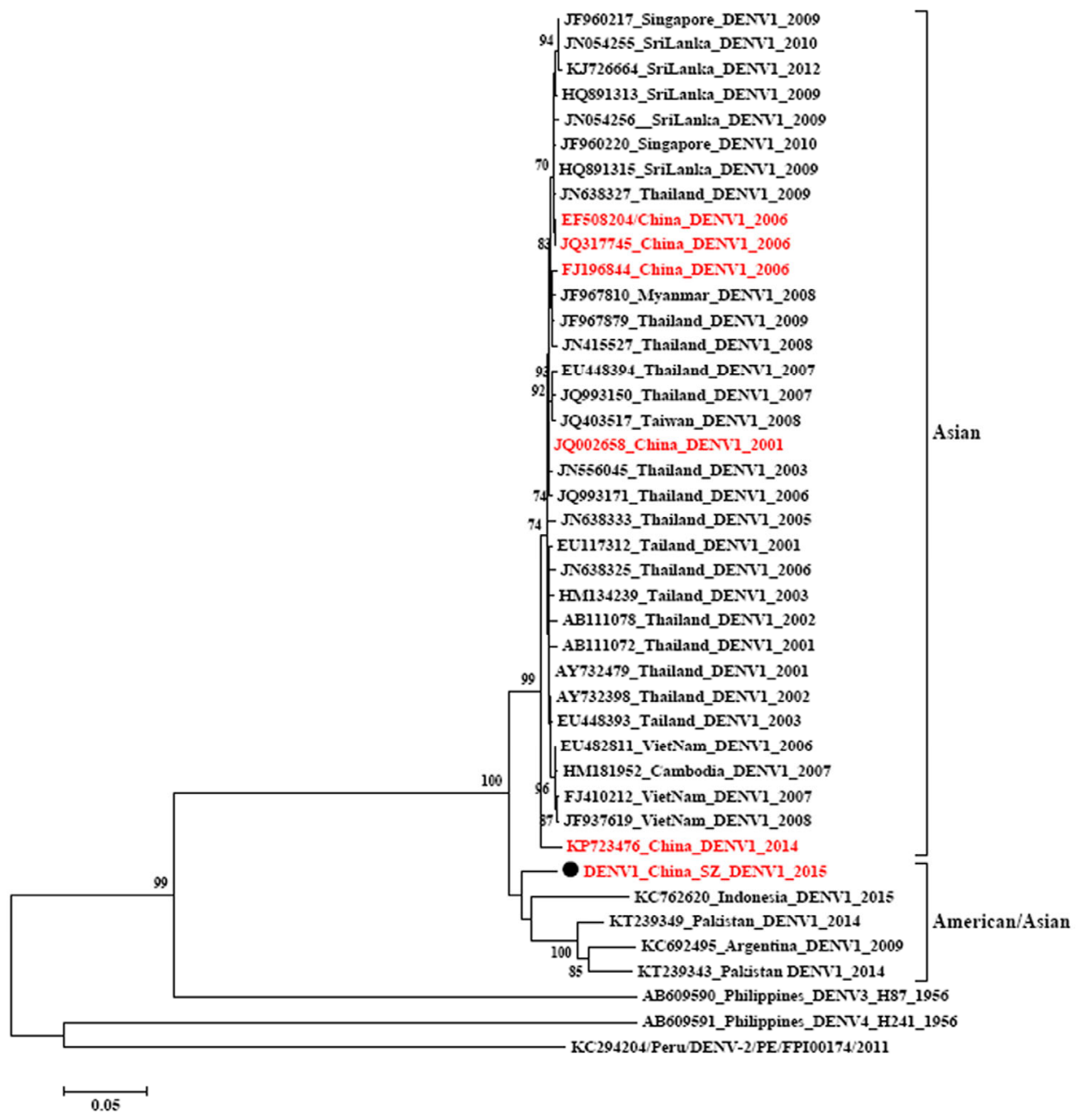

Figure 1 (color online) Phylogenetic analyses of DNEV-1 isolates based on the complete envelope gene using the Neighbor-Joining method. 
based on E gene for DENV2 is shown in Figure 2. The newly isolated DENV2/SZ/2015 belonged to the genotype Asian II, clustering closely with two former China isolates in 1987 and 1989. The E protein of these strains share 99\% amino acid homology. This finding shows the newly isolated DENV2 strain has been stable in China for many years.

To study the antiviral activity of CPI on DENV, VERO cells were infected at $1 \mathrm{TCID}_{50} /$ cell $(50 \%$ tissue culture infective dose per cell). At the time of infection, a final concentration of $20 \mu \mathrm{mol} \mathrm{L}{ }^{-1}$ CPI was added to the culture medium. Control cells were exposed to $1 \%$ dissolved in dimethyl sulfoxide (DMSO), which was used to dissolve the drug. Morphological changes of infected cells were examined by phase-contrast microscopy at 72 hour post infection (hpi). Microscopic examination revealed that the CPE of both DENV1 and DENV2 on the VERO cells was noticeably inhibited by CPI (Figure 3).
Viral genome copies in cells were determined for each group by quantitative real-time PCR. The copy number of GAPDH was used as an internal control. As shown in Figure $4 \mathrm{~A}$, in DENV1 infected cells, viral genome copies in cells treated with $20 \mu \mathrm{mol} \mathrm{L}{ }^{-1}$ CPI fell substantially to $21 \%$ compared to the control group. Replication of DENV2 also decreased to $17 \%$ of the control group when $20 \mu \mathrm{mol} \mathrm{L}{ }^{-1} \mathrm{CPI}$ was added (Figure 4B). At meanwhile, synthesis of viral proteins was detected by Western blot. And expression of cellular GAPDH was utilized as control. The results are shown in Figure $4 \mathrm{C}$ and D. Synthesis of viral protein was inhibited by CPI in both DENV1 and DENV2 infected cells, while expression of internal cellular GAPDH was not obviously suppressed. The concentration necessary to reduce the number of plaques by $50 \%$ (50\% inhibitory concentration, $\mathrm{IC}_{50}$ ) was determined as previously (Wang et al., 2014b). The $\mathrm{IC}_{50}$ of CPI against DENV1 and DENV2 was 18.6 and $15.1 \mu \mathrm{mol} \mathrm{L}{ }^{-1}$, respectively.

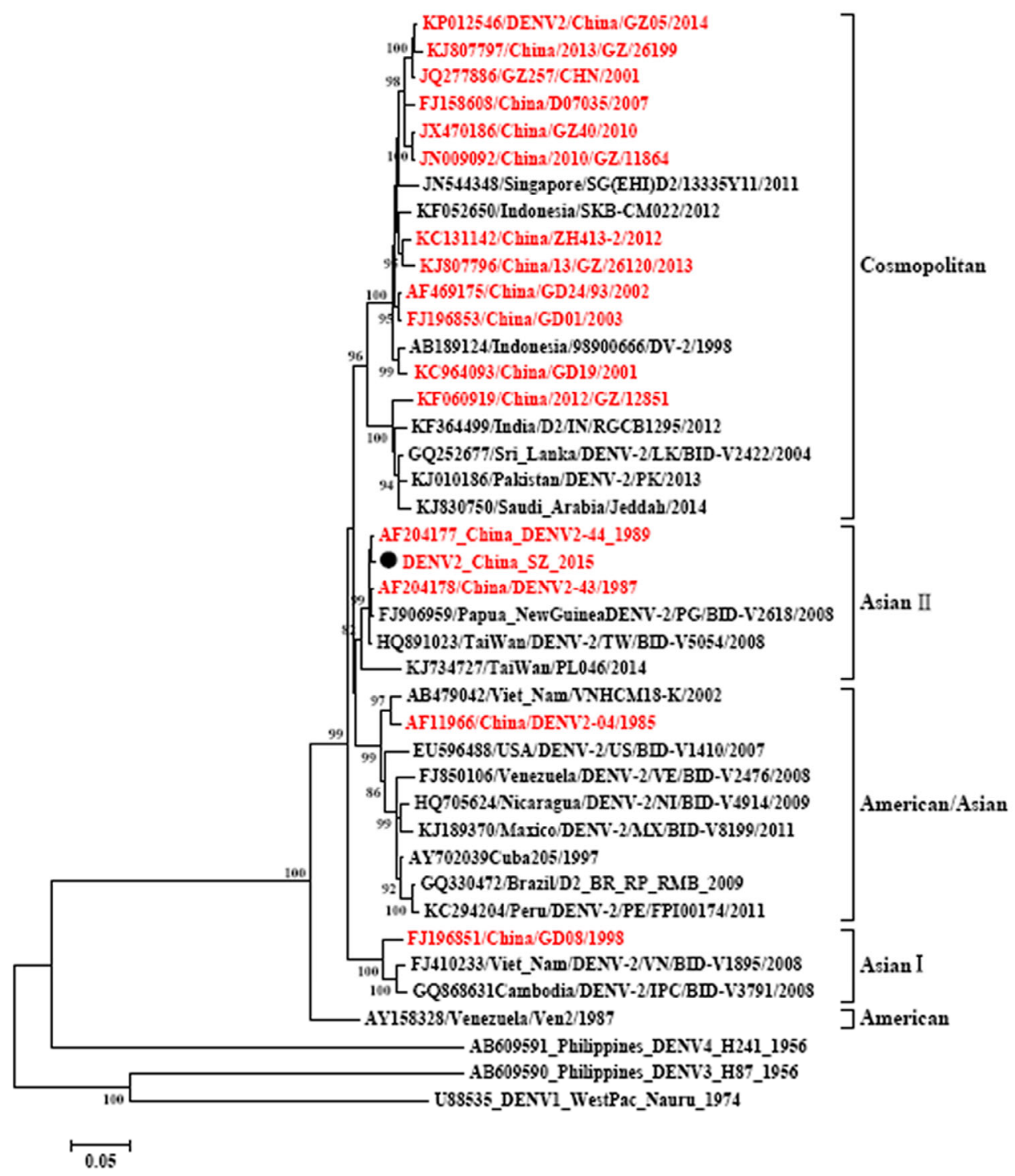

Figure 2 (color online) Phylogenetic analyses of DNEV-2 isolates based on the complete envelope gene using the Neighbor-Joining method. 

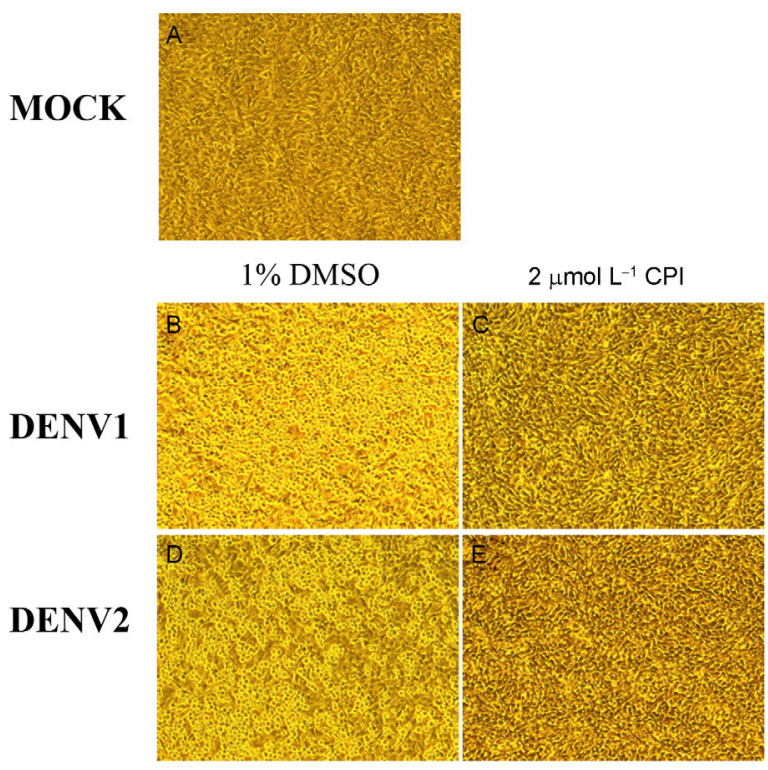

Figure 3 Effects of CPI on DENV1 and DENV2 infection. A, Mock infected VERO cells. B and D, DENV-1 and DENV-2 induced CPE in VERO cells. $\mathrm{C}$ and $\mathrm{E}$, Virus-induced $\mathrm{CPE}$ were reduced by the drug treatment.
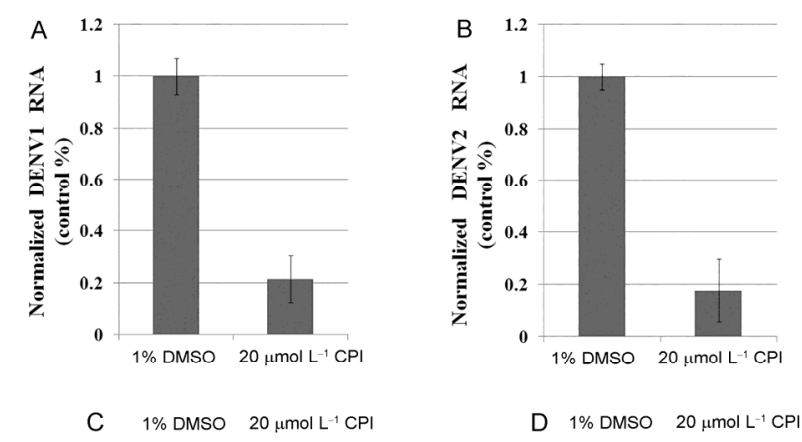

anti-DENV1
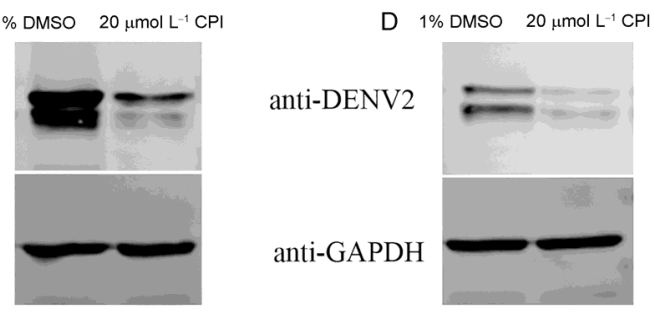

Figure 4 CPI inhibits both DENV1 and DENV2 replication in VERO cells. A and B, CPI inhibited the accumulation of viral RNA $(P<0.05)$. The experiment was performed in triplicate; bars represent means \pm SD. C and D, Synthesis of viral protein in VERO cells was reduced by the addition of CPI.

\section{DISCUSSION}

In 2014, a series of dengue fever outbreaks occurred in Guangdong, China. 423 cases were reported on 22 August, however, the number had reached 42,358 by 31 October (Jin et al., 2015). The exact cause of this outbreak is still not clear. However, as the exchange is getting more and more frequent for travelers between China and countries in Southeast Asia and Africa, where mosquito-borne infectious diseases are rampant, the prevention or treatment of dengue fever is of great importance. In this study, we characterized two DNEV strains and examined the anti-DENV activity of CPI, a flavonoid from the flavone subgroup. We found that CPI was highly effective against both DENV1 and DENV2 replication in cell cultures without obvious cytotoxicity.

Together with other viruses, DENV infection usually induces generation of neutralizing antibodies, which protect the individuals from viral infection and even provide life-long protection against the homologous serotype (Imrie et al., 2007). Unfortunately, in a secondary infection by a different DENV serotype, the antibody from the previous infection could cross-react with the virus to form a non- neutralizing complex and result in enhancement of viral infection through a mechanism known as antibody-depen- dent enhancement (Halstead, 2003). Thus co-circulation of multiple DENV serotypes could finally increase the risk of secondary infection and the percentage of severe dengue cases. In mainland China, DENV1 had been thought to be predominant and responsible for the epidemics of dengue fever in southern China for decades (Wu et al., 2011). However, the other three types of DENV had also been frequently detected (Jiang et al., 2012; Zhao et al., 2012a, 2012b, 2014). In the present study, we characterized a DENV2 strain from Shenzhen, Guangdong. Phylogenetic analyses revealed that DENV2/SZ/2015 isolate was closely related to former China isolates. This finding was consistent with previous report that DENV2 strains circulating in Guangdong have been stable since their introduction (Zhao et al., 2014), indicating that dengue fever cannot be simply treated as an imported epidemic disease anymore. A DENV1 strain was also determined. In contrast to the DENV2 strain, the DENV1/SZ/2015 isolate was not very similar to former China isolates, but genetically close to the Southeast Asian isolates. This result suggested that the DENV1 isolate might be transmitted into China by the mosquitoes or travelers in the recent years, reminding us the risk for new DENV1 outbreak. Besides local dengue outbreak, there is still threaten from outside, especially from tropical and subtropical area. To conclude, our data further confirm that multiple serotypes of DNEV are coexisting in mainland China. Genetic diversities and various origins make the DENV threaten much more serious and complicated.

Plenty of works have been done to explore clinical therapy against DENV infection. Several neutralizing antibodies have been characterized and showed potent neutralizing activity against DENV (Dejnirattisai et al., 2015; Fibriansah et al., 2015; Rouvinski et al., 2015; Smith et al., 2013). DENV subunit vaccines are being developed, too (Coller et al., 2011). However, none of these are currently clinically available. Plants, including Chinese herbal formulations, have been used to treat human diseases for centuries. Additionally, antiviral activities have also been identified in several hundred natural compounds worldwide. For 
example, lots of flavonoids possess antiviral activity, which are a large group of naturally occurring phenylchromones and can be found in fruits, vegetables, tea, soy foods, and herbs. Chrysin is a member from the flavone subgroup of flavonoid and has shown antiviral activity in our previous assay against enterovirus 71 (Wang et al., 2014b). As phosphorylated flavonoids usually demonstrated relatively stronger binding affinities and enhanced activity compared with non-phosphorylated forms (Chen et al., 2004, 2007). In the present study, we tested anti-DENV activity for CPI, the phosphate ester for chrysin. As expected, CPI was highly effective against infectious both DENV1 and DENV2 replication in cell cultures. CPI protected infected VERO cells from DENV induced CPE. Both viral genome replication and viral protein expression was substantially inhibited by the flavonoid. At meanwhile, no obvious cytotoxicity was observed, because VERO cells grew well and expression for cellular GAPDH was not affected in the control group. This finding of anti-DENV activity of natural compound was encouraging, because there are still a great of population still relies on traditional medicine for primary health care. Nevertheless, the inhibitory concentration for CPI at micromolar range was relatively high, we will try other modifications of the flavones by organic synthesis to get more potent inhibitors.

In conclusion, we characterized two clinical DENV isolates and provided meaningful information to understand the DENV epidemic in China. We also demonstrated that CPI exerted a strong inhibitory effect on DENV replication. This result is particularly important because no effective antiviral drug is currently available for the prevention, treatment, and control of DENV infection.

\section{MATERIALS AND METHODS}

\section{Cell culture and drug treatment}

African green monkey kidney cells (Vero; ATCC, USA) were propagated and maintained in Dulbecco's Modified Eagle Medium (HyClone, Australia) supplemented with $10 \%$ fetal bovine serum (Invitrogen, USA) plus $100 \mathrm{U} \mathrm{mL}^{-1}$ penicillin and $100 \mu \mathrm{g} \mathrm{mL} L^{-1}$ streptomycin at $37^{\circ} \mathrm{C}$ with $5 \%$ $\mathrm{CO}_{2}$. Cell numbers and proliferation were determined by direct cell number counting using CountStar (Inno-Alliance Biotech, Beijing) after staining with trypan blue. CPI was synthesized from chrysin (5,7-dihydroxyflavone, $\mathrm{C}_{15} \mathrm{H}_{10} \mathrm{O}_{4}$, Mr: 254.24) by using a simplified Atheron-Todd reaction as described previously (Wang et al., 2014b). For cell experiments, CPI was dissolved in dimethyl sulfoxide (DMSO) and then diluted in culture medium. To avoid toxicity or interference of the solvent, the maximum concentration of DMSO in the cell test medium was less than $0.1 \%$.

\section{Virus isolation and identification}

Eight patients with the clinical symptoms of fever, chill, severe myalgia and confusion were diagnosed with dengue virus infection by Shenzhen Third People's Hospital. Acute phase serum from the patients was collected and inoculated in VERO cells. Three samples induced complete cytopathic effects (CPE), from which culture supernatant was collected. Viral RNA was extracted from $140 \mu \mathrm{L}$ cell culture supernatant by using viral RNA mini kit (Qiagen, Germany), and reverse transcribed using the Superscript First-Strand Synthesis System (Invitrogen, USA) in a $20 \mu \mathrm{L}$ reaction mixture with $1.2 \mu \mathrm{g}$ total RNA and $50 \mathrm{ng}$ random hexamers according to the manufacturer's instructions. cDNA sam-

Table 1 Primers utilized in genome amplification for DENV1 and DENV2

\begin{tabular}{|c|c|c|}
\hline Target & Forward Primer & Reverse Primer \\
\hline \multirow{8}{*}{ DENV1 } & AGTTGTTAGTCTACGTGGACC & CGTTCGTCGACACACAAAGT \\
\hline & GTCACAAACCCTGCCGTCCT & CCTAGCCATGTCAGCAGAATC \\
\hline & CGCATGGGACTTCGGTTCTAT & CCTGACCCTGCAGAGACC \\
\hline & TCAGCACAACTACAGACCAG & GCTTTAAGGAGAATGGTGAGT \\
\hline & GGAATCATGGCTGTTGGAATA & TGCCATTTCAGAAGCGACAAC \\
\hline & CCAGAGATTGAGGACGAGGTG & TCATGAGCTCCACAAACG \\
\hline & GTTATCTAGCAGGAGCAGGTC & GGTGTGCGCGTGTCAACTTTC \\
\hline & GGAAGCCAACATATGAAAGAGACG & CCGCGGAGAACCTGTTGATTCAACA \\
\hline \multirow{9}{*}{ DENV2 } & AGTTGTTAGTCTACGTGCACC & TGGTAACGGCAGGTCTAA \\
\hline & GGATGCGGATTATTTGGA & GTCTTGTTACTGAGCGGATTC \\
\hline & TTCACGCAGCACCTCACT & TGTGTATGATAGCCTGGTCTGT \\
\hline & TGGAAGATTGAGAAAGCCTC & ATTTGGGACGCACAAGATAG \\
\hline & GAAAGAATCCAAGAGCCGTCC & CTTCAGGCGTGTTGATGTTA \\
\hline & AGCACAAAGAAGAGGGAGAGT & CATCCGATAGCGAGAAGG \\
\hline & CGTGGCAACAACTTTCAT & GTCTGGCTCGTATGTGGC \\
\hline & GGGAGTCGTCACCAAACC & AGACTCCTTCTCCСТCCATC \\
\hline & LACCAACACCAAGAGGCACAG & AGAACCTGTTGATTCAACAGC \\
\hline
\end{tabular}


ples were then subjected to PCR detection by using primers: DENV-F (5'-GTGCACACATTGACAGAACA-3') and DENV-R (5'-CTTTCTATCCAATAACCCAT-3'), following the guideline of Chinese Center for Disease Control and Prevention. After sequencing, positive samples were stored at $-80^{\circ} \mathrm{C}$ until use.

\section{Complete genome sequencing}

Primers were designed on the basis of available GenBank genomic sequences of the DENV1 (KM204119) and DENV2 (AF204177), as shown in Table 1. Viral RNA was extracted and reverse transcribed by using random hexamers primers. Overlapping fragments covering each viral genome were then amplified. The PCR products were sequenced and assembled manually.

\section{Sequence alignment and phylogenetic analysis}

The full-length genome sequences of DENV1/China/ SZ/2015 and DENV2/China/SZ/2015 were aligned with 42 and 41 complete sequences using ClustalW, respectively (http://www.clustal.org/). All sequences were deposited in GenBank (accession numbers as shown in figure). Phylogenetic trees for DENV1 and DENV2 based on the complete envelope gene regions were constructed with Molecular Evolutionary Genetics Analysis (MEGA) version 5.0 (Tamura et al., 2011). The evolutionary history was inferred using the Neighbor-Joining method (Saitou and Nei, 1987). The optimal tree with the sum of branch length $=1.79014943$ is shown. The percentage of replicate trees in which the associated taxa clustered together in the bootstrap test (1,000 replicates) are shown next to the branches (Sanderson and Wojciechowski, 2000). The tree is drawn to scale, with branch lengths in the same units as those of the evolutionary distances used to infer the phylogenetic tree. The evolutionary distances were computed using the Tamura-Nei method (Tamura and Nei, 1993) and are in the units of the number of base substitutions per site. The rate variation among sites was modeled with a gamma distribution (shape parameter $=1$ ). The analysis involved 41 and 42 nucleotide sequences respectively.

\section{Viral infection}

DENV-1 and DENV-2 viruses were propagated in VERO cells. When complete CPE was observed, culture supernatant was harvested to yield viruses at $10^{5} \sim 10^{6} \mathrm{TCID}_{50} \mathrm{~mL}^{-1}$ (50\% tissue culture infectious doses) determined by using the Reed-Muench method (Reed and Muench, 1938). Approximately $10^{5}$ cells were seeded into 24 -well plate $12 \mathrm{~h}$ before infection. When reached $90 \%$ confluences, cells were infected with DENV-1 or DENV-2 viruses at 1 TCID $_{50}$ cell $^{-1}$. CPI was added to cell cultures at the time of infection. Western blotting and quantitative real-time PCR were performed 24 hours post-infection (hpi) as described below. Representative results are shown.

\section{Quantitative real-time PCR}

Relative quantitative real-time PCR was conducted on an ABI Prism 7000 Real-time PCR System (Applied Biosystems, USA) by using a Power SYBR Green PCR Master Kit (Applied Biosystems). Reactions were $2 \mu \mathrm{L}$ cDNA, $1 \mu \mathrm{L}$ of each primer and $25 \mu \mathrm{L}$ Power SYBR Green PCR Master Mix in $50 \mu \mathrm{L}$ volumes. Efficiency-corrected relative quantitation was used with GAPDH as an internal control (Pfaffl, 2001).

\section{Western blot analysis}

Cells were pelleted by centrifugation and lysed in buffer containing $100 \mathrm{mmol} \mathrm{L}^{-1} \mathrm{NaCl}, 20 \mathrm{mmol} \mathrm{L}^{-1}$ Tris ( $\mathrm{pH} 8.0$ ), $0.5 \%$ NP-40, $0.25 \%$ sodium deoxycholate, and $1 \mathrm{mmol} \mathrm{L}^{-1}$ ethylene diamine tetraacetic acid (EDTA) with protease inhibitor cocktail (Roche, USA). Supernatant was collected and aliquots of cell lysate were electrophoresed on $10 \%$ sodium dodecyl sulfate polyacrylamide gel electrophoresis (SDS-PAGE) gels and transferred to nylon polyvinylidene difluoride membranes (PVDF, Hybond P, Piscataway, USA). The membranes were blocked with $5 \%$ bovine serum albumin (BSA), and proteins on the membrane were probed with primary antibodies at $4^{\circ} \mathrm{C}$ overnight followed by incubation with corresponding IRD Fluor 680-labeled IgG secondary antibody (Li-Cor Inc., USA) for $1 \mathrm{~h}$ at room temperature. After washing, the membranes were scanned with the Odyssey infrared imaging system (Li-Cor Inc., USA) at a wavelength of $700 \mathrm{~nm}$, and the molecular sizes of the developed proteins were determined by a comparison with prestained protein markers (Fermentas, USA). The DENV1 and DENV2 were detected by anti-DENV monoclonal antibody (Abcam, USA). To control for protein loading, levels of the housekeeping protein GAPDH were assessed using mouse anti-GAPDH (Beyotime, Suzhou).

\section{Statistical analysis}

At least three independent experiments were carried out for each variable. Statistical significance was assessed with SSPS version 10.0. Differences were considered statistically significant at a threshold of $P<0.05$. All results are presented as mean \pm SD.

Compliance and ethics The author(s) declare that they have no conflict of interest.

Acknowledgements This work was supported by the National Natural Science Foundation of China (31300154).

Bhatt, S., Gething, P.W., Brady, O.J., Messina, J.P., Farlow, A.W., Moyes, C.L., Drake, J.M., Brownstein, J.S., Hoen, A.G., Sankoh, O., Myers, M.F., George, D.B., Jaenisch, T., Wint, G.R., Simmons, C.P., Scott, T.W., Farrar, J.J., and Hay, S.I. (2013). The global distribution and burden of dengue. Nature 496, 504-507.

Chen, B., and Liu, Q. (2015). Dengue fever in China. Lancet 385, 1621-1622. 
Chen, X.L., Qu, L.B., Zhang, T., Liu, H.X., Yu, F., Yu, Y., Liao, X., and Zhao, Y.F. (2004). The nature of phosphorylated chrysin-protein interactions involved in noncovalent complex formation by electrospray ionization mass spectroscopy. Anal Chem 76, 211-217.

Chen, X.L., Yu, Z.Q., Qu, L.B., Yuan, J.W., Lu, J.S., and Zhao, Y.F. (2007). Phosphorylated modification of genistein and their interaction with lysozyme. Yao Xue Xue Bao 42, 396-400.

Coller, B.A., Clements, D.E., Bett, A.J., Sagar, S.L., and Ter Meulen, J.H. (2011). The development of recombinant subunit envelope-based vaccines to protect against dengue virus induced disease. Vaccine 29, 7267-7275.

Dejnirattisai, W., Wongwiwat, W., Supasa, S., Zhang, X., Dai, X., Rouvinski, A., Jumnainsong, A., Edwards, C., Quyen, N.T., Duangchinda, T., Grimes, J.M., Tsai, W.Y., Lai, C.Y., Wang, W.K., Malasit, P., Farrar, J., Simmons, C.P., Zhou, Z.H., Rey, F.A., Mongkolsapaya, J., and Screaton, G.R. (2015). A new class of highly potent, broadly neutralizing antibodies isolated from viremic patients infected with dengue virus. Nat Immunol 16, 170-177.

Fibriansah, G., Tan, J.L., Smith, S.A., de Alwis, R., Ng, T.S., Kostyuchenko, V.A., Jadi, R.S., Kukkaro, P., de Silva, A.M., Crowe, J.E., and Lok, S.M. (2015). A highly potent human antibody neutralizes dengue virus serotype 3 by binding across three surface proteins. Nat Commun 6, 6341.

Halstead, S.B. (2003). Neutralization and antibody-dependent enhancement of dengue viruses. Adv Virus Res 60, 421-467.

Higa, Y. (2011). Dengue vectors and their spatial distribution. Trop Med Health 39, 17-27.

Holmes, E.C., and Twiddy, S.S. (2003). The origin, emergence and evolutionary genetics of dengue virus. Infect Genet Evol 3, 19-28.

Imrie, A., Meeks, J., Gurary, A., Sukhbaatar, M., Truong, T.T., Cropp, C.B., and Effler, P. (2007). Antibody to dengue 1 detected more than 60 years after infection. Viral Immunol 20, 672-675.

Jiang, T., Yu, X.D., Hong, W.X., Zhou, W.Z., Yu, M., Deng, Y.Q., Zhu, S.Y., Qin, E.D., Wang, J., Qin, C.F., and Zhang, F.C. (2012). Co-circulation of two genotypes of dengue virus serotype 3 in Guangzhou, China, 2009. Virol J 9, 125.

Jin, X., Lee, M., and Shu, J. (2015). Dengue fever in China: an emerging problem demands attention. Emerg Microbes Infect 4, e3.

Johari, J., Kianmehr, A., Mustafa, M.R., Abubakar, S., and Zandi, K. (2012). Antiviral activity of baicalein and quercetin against the Japanese Encephalitis virus. Int J Mol Sci 13, 16785-16795.

Lyu, S.Y., Rhim, J.Y., and Park, W.B. (2005). Antiherpetic activities of flavonoids against herpes simplex virus type 1 (HSV-1) and type 2 (HSV-2) in vitro. Arch Pharm Res 28, 1293-1301.

Normile, D. (2013). Tropical medicine. Surprising new dengue virus throws a spanner in disease control efforts. Science 342, 415.

Pfaffl, M.W. (2001). A new mathematical model for relative quantification in real-time RT-PCR. Nucleic Acids Res 29, e45.

Reed, L.J., and Muench, H. (1938). A simple method of estimating fifty per cent endpoints. Amjhyg 27, 493-497.

Rouvinski, A., Guardado-Calvo, P., Barba-Spaeth, G., Duquerroy, S., Vaney, M.C., Kikuti, C.M., Navarro Sanchez, M.E., Dejnirattisai, W., Wongwiwat, W., Haouz, A., Girard-Blanc, C., Petres, S., Shepard, W.E., Despres, P., Arenzana-Seisdedos, F., Dussart, P., Mongkolsapaya, J., Screaton, G.R., and Rey, F.A. (2015). Recognition determinants of broadly neutralizing human antibodies against dengue viruses. Nature $520,109-113$.
Saitou, N., and Nei, M. (1987). The neighbor-joining method: a new method for reconstructing phylogenetic trees. Mol Biol Evol 4, 406-425.

Sanderson, M.J., and Wojciechowski, M.F. (2000). Improved bootstrap confidence limits in large-scale phylogenies, with an example from Neo-Astragalus (Leguminosae). Syst Biol 49, 671-685.

Smith, S.A., de Alwis, A.R., Kose, N., Harris, E., Ibarra, K.D., Kahle, K.M., Pfaff, J.M., Xiang, X., Doranz, B.J., de Silva, A.M., Austin, S.K., Sukupolvi-Petty, S., Diamond, M.S., and Crowe, J.E., Jr. (2013). The potent and broadly neutralizing human dengue virus-specific monoclonal antibody $1 \mathrm{C} 19$ reveals a unique cross-reactive epitope on the bc loop of domain II of the envelope protein. MBio 4, e00873-00813.

Tamura, K., and Nei, M. (1993). Estimation of the number of nucleotide substitutions in the control region of mitochondrial DNA in humans and chimpanzees. Mol Biol Evol 10, 512-526.

Tamura, K., Peterson, D., Peterson, N., Stecher, G., Nei, M., and Kumar, S. (2011). MEGA5: molecular evolutionary genetics analysis using maximum likelihood, evolutionary distance, and maximum parsimony methods. Mol Biol Evol 28, 2731-2739.

Thomas, S.J., and Endy, T.P. (2011). Critical issues in dengue vaccine development. Curr Opin Infect Dis 24, 442-450.

Vasilakis, N., and Weaver, S.C. (2008). The history and evolution of human dengue emergence. Adv Virus Res 72, 1-76.

Wang, J., Su, H., Zhang, T., Du, J., Cui, S., Yang, F., and Jin, Q. (2014a). Inhibition of Enterovirus 71 replication by 7-hydroxyflavone and diisopropyl-flavon7-yl Phosphate. PLoS One 9, e92565.

Wang, J., Zhang, T., Du, J., Cui, S., Yang, F., and Jin, Q. (2014b). Anti-enterovirus 71 effects of chrysin and its phosphate ester. PLoS One 9, e89668.

Wu, J.Y., Lun, Z.R., James, A.A., and Chen, X.G. (2010). Dengue Fever in mainland China. Am J Trop Med Hyg 83, 664-671.

Wu, W., Bai, Z., Zhou, H., Tu, Z., Fang, M., Tang, B., Liu, J., Liu, L., and Chen, W. (2011). Molecular epidemiology of dengue viruses in southern China from 1978 to 2006. Virol J 8, 322.

Zandi, K., Lim, T.H., Rahim, N.A., Shu, M.H., Teoh, B.T., Sam, S.S., Danlami, M.B., Tan, K.K., and Abubakar, S. (2013). Extract of Scutellaria baicalensis inhibits dengue virus replication. BMC Complement Altern Med 13, 91.

Zandi, K., Teoh, B.T., Sam, S.S., Wong, P.F., Mustafa, M.R., and Abubakar, S. (2011). Antiviral activity of four types of bioflavonoid against dengue virus type-2. Virol J 8, 560 .

Zhao, H., Deng, Y.Q., Hong, W.X., Yu, X.D., Jiang, T., Yu, M., Hu, F.Y., Zhu, S.Y., Li, X.F., Song, K.Y., Qin, E.D., Zhang, F.C., and Qin, C.F. (2012a). Complete genome sequence of dengue virus serotype 2 Cosmopolitan genotype strain in Guangdong, China. J Virol 86, 13808-13809.

Zhao, H., Yu, X.D., Zhang, X.Y., Jiang, T., Hong, W.X., Yu, M., Hu, F.Y., Zhu, S.Y., Qin, E.D., Deng, Y.Q., Qin, C.F., and Zhang, F.C. (2012b). Complete genome sequence of a dengue virus serotype 4 strain isolated in Guangdong, China. J Virol 86, 7021-7022.

Zhao, H., Zhao, L., Jiang, T., Li, X., Fan, H., Hong, W., Zhang, Y., Zhu, Q., Ye, Q., Tong, Y., Cao, W., Zhang, F., and Qin, C. (2014). Isolation and characterization of dengue virus serotype 2 from the large dengue outbreak in Guangdong, China in 2014. Sci China Life Sci 57, 1149-1155.

Open Access This article is distributed under the terms of the Creative Commons Attribution License which permits any use, distribution, and reproduction in any medium, provided the original author(s) and source are credited. 